\title{
Hydrothermal generation scheduling package: A genetic based approach
}

\author{
H.-C.Chang \\ P.-H.Chen
}

\begin{abstract}
Novel solution algorithms and results based on a genetic algorithm for solving the hydrothermal generation scheduling (HTGS) problem are presented. This is a nonlinear, combinational optimisation problem which aims to minimise the total fuel costs of a power system while satisfying various local and coupling constraints. This results in a complete and efficient HTGS software package for system operation planning needs. In the thermal unit commitment subproblem, the difficult minimal uptime/downtime constraints are embedded and satisfied throughout the proposed encoding and decoding algorithms. Therefore, the global optimum of the problem can be approached with rather high probability. In the hydroelectric scheduling subproblems, complete solution algorithms and encoding/decoding techniques are proposed for solving different types of hydro plants involving hydraulically independent plants (HIPs), hydraulically coupled plants (HCPs), and pump-storage $(\mathrm{P} / \mathrm{S})$ plants. In the proposed approach, the hydraulically coupled plants which are located on the same river are solved concurrently. The difficult water balance constraints caused by hydraulic coupling are embedded and satisfied throughout the proposed encoding and decoding algorithm. The software package is applied with great success to the actual Taipower system, which consists of 34 thermal units, two HIPs, three HCPs, and four P/S units.
\end{abstract}

\section{List of symbols}

$P_{h j}^{t} \quad=$ power generation of hydro plant $j$ in hour $t$

$P_{s i}^{t} \quad=$ power generation of thermal unit $i$ in hour $t$

$F_{i}^{t}\left(P_{s i}^{t}\right)=$ production cost for $P_{s i}^{t}$

$T \quad=$ number of scheduling hours

$N_{h} \quad=$ number of hydro plants

$N_{s} \quad=$ number of thermal units

\section{(C) IEE, 1998}

IEE Proceedings online no. 19981986

Paper received 11th August 1997

H.-C. Chang is with the Department of Electrical Engineering, National Taiwan University of Science and Technology, Taipei, Taiwan

P.-H. Chen is with the Department of Electrical Engineering, St. John's and St. Mary's Institute of Technology, Tamsui, Taiwan

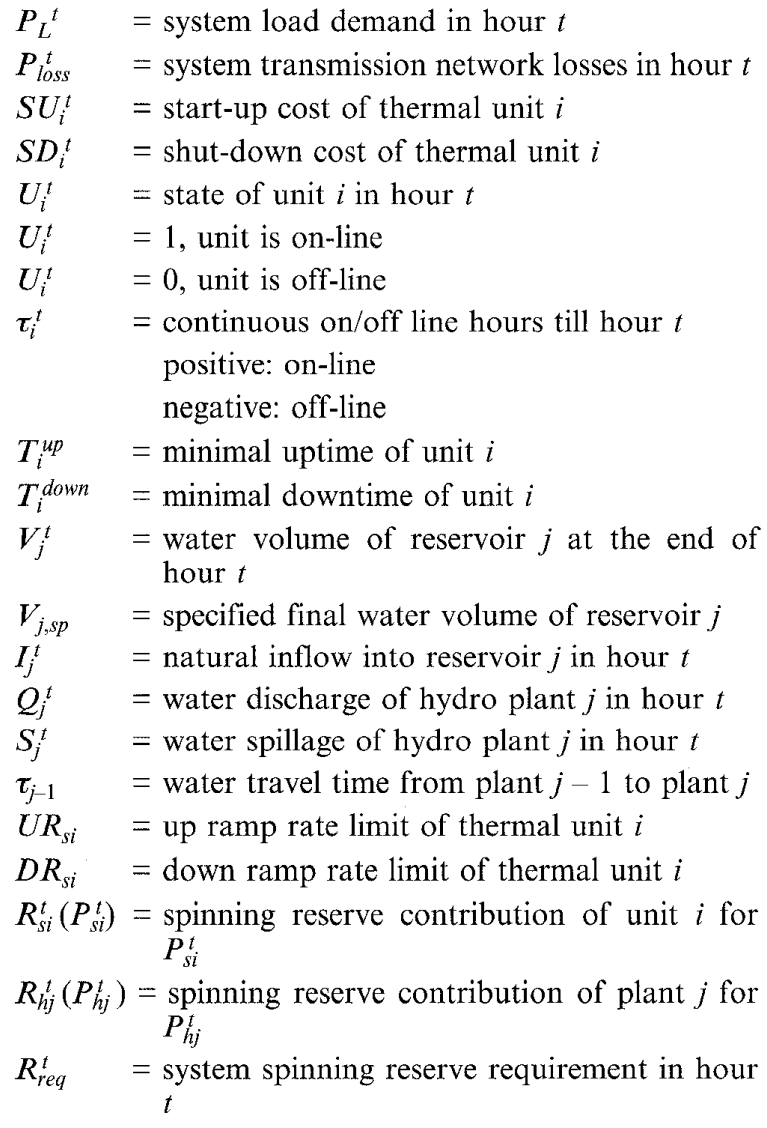

\section{Introduction}

The operation of a power system is characterised by having to maintain a high degree of economy and reliability [1]. In view of this, hydrothermal generation scheduling (HTGS) plays an important role in power system operation planning. HTGS is mainly concerned with both hydro unit scheduling and thermal unit dispatching, and is more difficult than the scheduling of an all-thermal system. The objective of HTGS is to determine the optimal schedules and generation output of both hydro and thermal units while satisfying various constraints, in order to meet forecasted load demand fluctuation over a future period.

The exact optimal solution to the HTGS problem can be obtained by exhaustive enumeration of all hydro and thermal unit combinations at each time period. However, the burden of computation makes this unacceptable for realistic applications. Conven- 
tional methods for solving the HTGS problem are based on decomposition approaches that involve a hydro and a thermal subproblem [2-4]. These two subproblems are usually coordinated by Lagrange multipliers, then the optimal generation schedules of both hydro and thermal units are obtained via repetitive hydrothermal iterations. A well-recognised difficulty is that the solutions to these two subproblems may oscillate between maximum and minimum generations with slight changes of the multipliers [4]. As a result, the solution cost usually gets stuck at a local optimum rather than at the global optimum. However, the optimality of solution is very important to electric utility. Even a small reduction in percentage production cost may lead to a large saving of money. Obviously, a complete and efficient algorithm for solving the HTGS problem is still in demand.

Recently, a global optimisation technique known as genetic algorithm (GA) has emerged as a candidate for many optimisation applications due to its flexibility and efficiency. GA is a stochastic searching algorithm. It combines an artificial 'survival of the fittest' principle with genetic operators abstracted from nature to form a surprisingly robust mechanism that is very effective at finding optimal solutions to complex realworld problems $[5,6]$. GA has been successfully applied in various areas such as loss minimisation [7], hydroelectric scheduling [8], economic dispatch [9], and so on.

In this paper, a new GA approach is developed for solving the HTGS problem for the coming $24 \mathrm{~h}$ period. One of the advantages of the new approach is the use of stochastic operators rather than deterministic rules to obtain the global optimum in order to escape from local optimums where other methods might land. In the proposed GA approach, the thermal subproblem can be solved entirely independently. No multiplier coordination is required in the solution procedure, hence the oscillation problem can be completely precluded. In addition, unit commitment (UC) is performed for the remaining thermal load profile (load profile minus hydro generations) and the resulting thermal cost is returned as the 'fitness' of the hydro generation schedule. The optimal solutions of both hydro and thermal units are concurrently obtained within the evolutionary process of fitness. A representative test example based on the actual Taipower system is presented and analysed to illustrate the capability of the proposed approach in practical applications.

\section{Problem description and formulation}

\subsection{Objective function and constraints}

The HTGS deals with the problem of obtaining the optimal generation schedules for both hydro and thermal units. It aims to minimise the total fuel costs of thermal units while satisfying various constraints. With discretisation of the total scheduling time into a set of shorter time intervals (say, one hour per interval), the HTGS can be mathematically formulated as a constrained combinational optimisation problem as follows:

$$
\begin{aligned}
\min \sum_{t=1}^{T} \sum_{i=1}^{N_{s}}\left[F_{i}^{t}\left(P_{s i}^{t}\right)\right. & +S U_{i}^{t}\left(U_{i}^{t-1}, U_{i}^{t}\right) \\
& \left.+S D_{i}^{t}\left(U_{i}^{t-1}, U_{i}^{t}\right)\right]
\end{aligned}
$$

subject to the following constraints:

452 (i) System power balance

$$
\sum_{i=1}^{N_{s}} P_{s i}^{t}+\sum_{j=1}^{N_{h}} P_{h j}^{t}-P_{L}^{t}-P_{\text {loss }}^{t}=0
$$

(ii) Water dynamic balance with travel time

$$
V_{j}^{t}=V_{j}^{t-1}+I_{j}^{t}+Q_{j-1}^{t-\tau_{j-1}}+S_{j-1}^{t-\tau_{j-1}}-Q_{j}^{t}-S_{j}^{t}
$$

(iii) Thermal generation and ramp rate limits

$$
\begin{aligned}
\max \left(\underline{P_{s i}}, P_{s i}^{t-1}-D R_{s i}\right) & \leq P_{s i}^{t} \\
& \leq \min \left(\overline{P_{s i}}, P_{s i}^{t-1}+U R_{s i}\right)
\end{aligned}
$$

(iv) Minimal uptime

$$
\tau_{i}^{t-1} \geq T_{i}^{u p} \times U_{i}^{t-1}\left(1-U_{i}^{t}\right)
$$

(v) Minimal downtime

$$
\left|\tau_{i}^{t-1}\right| \geq T_{i}^{\text {down }} \times\left(1-U_{i}^{t-1}\right) U_{i}^{t}
$$

(vi) Hydro discharge limits

$$
\underline{Q_{j}} \leq Q_{j}^{t} \leq \overline{Q_{j}}
$$

(vii) Reservoir limits

$$
\underline{V_{j}} \leq V_{j}^{t} \leq \overline{V_{j}}
$$

(viii) System spinning reserve requirement

$$
\sum_{i=1}^{N_{s}} R_{s i}^{t}\left(P_{s i}^{t}\right)+\sum_{j=1}^{N_{h}} R_{h j}^{t}\left(P_{h j}^{t}\right) \geq R_{r e q}^{t}
$$

\subsection{Hydro plant classification}

Hydro plants differ, for example, in their watersheds, storage capacity, discharge requirements, and unit characteristics. We may group these units into the following categories:

(i) Run-of-river plant (ROR): A ROR plant has little storage capacity; water not flowing through the turbine is spilled over. Output of a ROR plant therefore depends heavily on river flow conditions and thus might not be optimally dispatched.

(ii) Hydraulically independent plant (HIP): An HIP is hydraulically isolated from other hydro plants. There is no coupling between individual plants except through the electric transmission network. Most of these plants have some storage capacity.

(iii) Hydraulically coupled plants (HCPs): In HCPs, the water outflow from one plant may be a very significant portion of the inflow to one or more other plants which are located downstream. The scheduling of HCPs is more complex and more difficult than the scheduling of other types of hydro plants because they are coupled both hydraulically and electrically.

(iv) Pumped-storage (P/S) plant: A P/S plant, which consists of an upper and a lower reservoir, is designed to save fuel costs by generating during peak load with water in the upper reservoir, which would be pumped up during light load hours.

\subsection{Equivalent hydro plant model}

The number of hydro units is generally much greater than the number of hydro plants. Therefore, in practical hydrothermal coordination problems, it is advantageous to model hydro generation at the plant (or reservoir) level to reduce the size of the problem. An equivalent plant model can be obtained using an off- 
line mathematical procedure which maximises the total plant generation output under different water discharge rates [2]. The generation output of an equivalent hydro plant is a function of the water discharge through the turbine and the net head (or the content of reservoir). The quadratic discharge-generation function used in this paper as a good approximation of hydro plant generation characteristics, considering the head effect, is:

$$
P_{h j}^{t}=\alpha_{j}^{t-1}\left(Q_{j}^{t}\right)^{2}+\beta_{j}^{t-1} Q_{j}^{t}+\gamma_{j}^{t-1}
$$

where coefficients $\alpha_{j}^{t-1}, \beta_{j}^{t-1}$ and $\gamma_{j}^{t-1}$ depend on the content of reservoir $j$ at the end of hour $t-1$. In this work, the read-in data include five groups of $\alpha, \beta, \gamma$ coefficients that relate to different storage volumes, from minimum to maximum. Then, the corresponding coefficients for any reservoir volume are calculated by using a linear interpolation between the two closest volumes [3].

Modelling of $\mathrm{P} / \mathrm{S}$ plants is divided into generating mode and pumping mode. In the generating mode, the characteristic of a $\mathrm{P} / \mathrm{S}$ plant is similar to normal hydro plants as shown in the first quadrant of Fig. 1. In the pumping mode, since all $\mathrm{P} / \mathrm{S}$ units of Taipower are designed for constant power pumping, the characteristic function of a $\mathrm{P} / \mathrm{S}$ plant is a discrete distribution as shown in the third quadrant of Fig. 1.

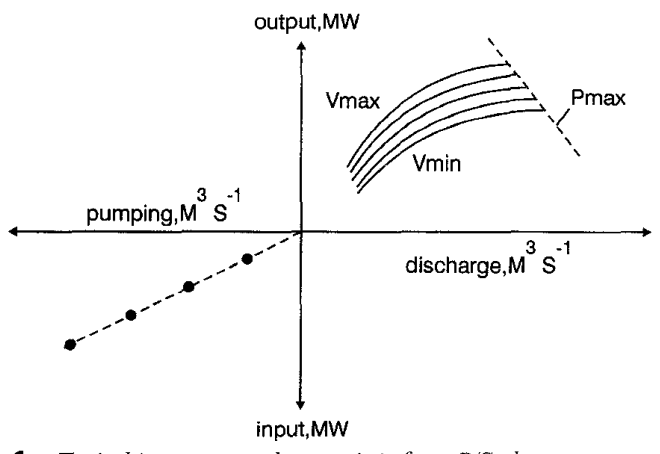

Fig. 1 Typical input-output characteristic for a P/S plant

\section{Genetic algorithm solution methodology}

\subsection{Brief review of the genetic algorithm}

The genetic algorithm (GA) is essentially a search algorithm based on the mechanics of natural selection and natural genetics. It combines solution evaluation with randomised, structured exchanges of information between solutions to obtain optimality. GA is a robust approach because no restrictions on the solution space are made during the search process. The power of this algorithm comes from its ability to exploit historical information structures from previous solution guesses in an attempt to increase the performance of future solution structures [5].

By simulating the 'survival of the fittest' criterion of Darwinian evolution among chromosome structures, the optimal solution is sought by randomised information exchange. While randomised, GA is not a simple random walk. It efficiently exploits historical information to speculate on new search points with expected improved performance. In every generation, a new set of artificial chromosomes is created using bits and pieces of the fittest of the old ones. The three prime operators associated with the GA are reproduction, crossover, and mutation.
Reproduction is simply an operation whereby an old chromosome is copied into a 'mating pool' according to its fitness value. More highly fitted chromosomes (i.e. with better values of the objective function) receive a greater number of copies in the next generation. Copying chromosomes according to their fitness values means that chromosomes with a higher value have a higher probability of contributing one or more offspring in the next generation.

Crossover is an extremely important component of the GA. It is a structured recombination operation. This operation is similar to that of two scientists exchanging information. This study applies a new crossover technique known as uniform crossover. The uniform crossover exchanges bits, according to a randomly generated mask, between the parent chromosomes to create two new chromosomes. The ' 1 ' in the random mask means bits swapping and the ' 0 ' means bits replicating, as shown in Fig. 2.

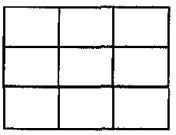

parent A

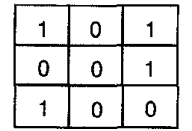

random mask

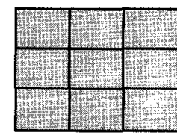

parent $B$
Fig. 2
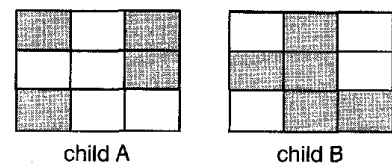

The uniform crossover

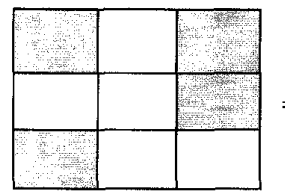

child A

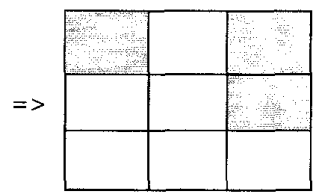

new child $A$
Fig.3 The mutation

Although reproduction and crossover effectively search and recombine existing chromosomes, they do not create any new genetic material in the population. Mutation is capable of overcoming this shortcoming. It is an occasional (with small probability) random alternation of a chromosome position, as shown in Fig. 3. This provides background variation and occasionally introduces beneficial materials into the population.

\subsection{Execution sequence}

The execution sequence for solving the HTGS problem is shown in Fig. 4: (i) Subtract the expected generation output of all hydro plants and nuclear units from the actual system load curve. The expected generation output of hydro plants can be obtained from historical records or by the peak-shaving method [10] (ii) Use GA to solve the optimal generation schedule for thermal units. This task is the so-called 'unit commitment'. (iii) Use GA to solve the optimal generation schedules for HIPs, HCPs, and $\mathrm{P} / \mathrm{S}$ plants in sequence. These tasks belong to the class of 'hydro-thermal coordination' which deals with not only hydro plants scheduling, but also thermal units dispatching. Fig. 5 depicts conceptually the proposed GA approach for hydrother- 
mal coordination. Each chromosome in the population corresponds to an encoding of the generation schedule. To solve the hydroelectric system, the HIP subprogram is solved first because it does not check spinning reserve. The remained selection is to execute HCP or $\mathrm{P} / \mathrm{S}$ subprogram first. The authors tried and found the two converged solutions from these two different sequences were nearly the same. Executing HCP first got a lower solution cost than executing $\mathrm{P} / \mathrm{S}$ first although the difference is less than $0.02 \%$.

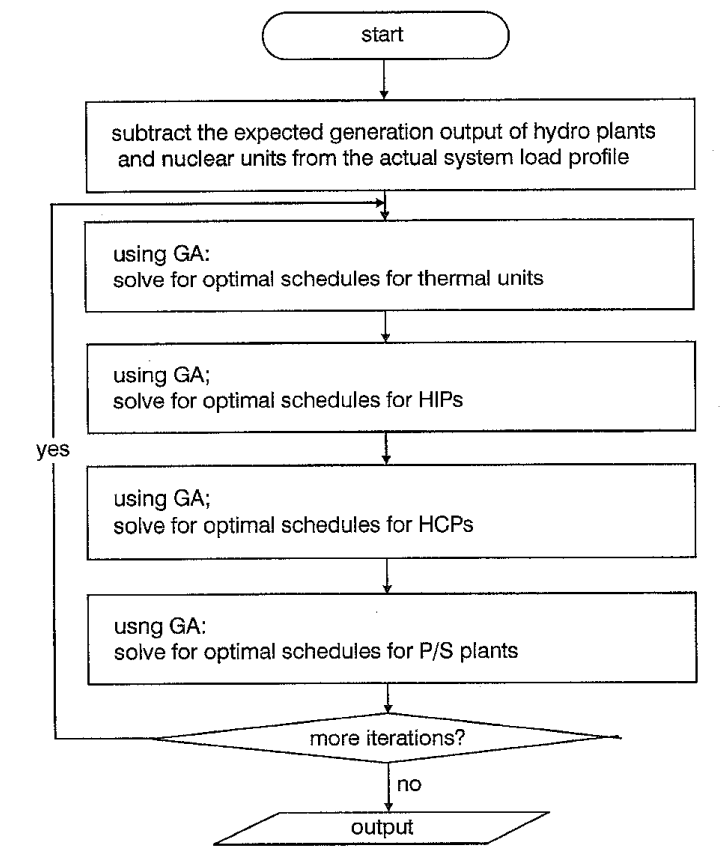

Fig. 4 Execution sequence for solving the HTGS problem

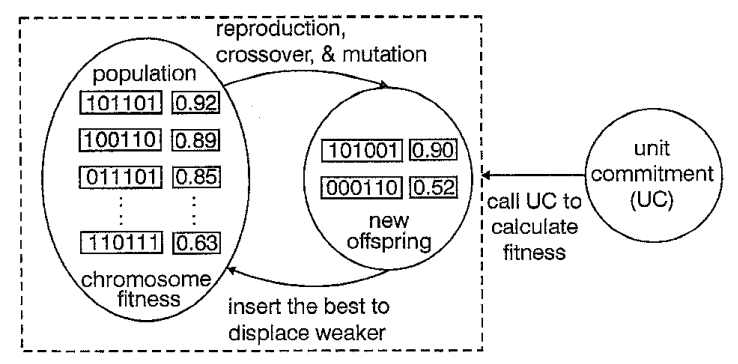

Fig.5 Proposed GA approach for hydrothermal coordination

\subsection{Encoding and decoding}

Implementation of a problem in a GA starts from the parameter encoding, i.e. the representation of the problem. The encoding must be carefully designed to utilise the GA's ability to efficiently transfer information between chromosome strings and achieve the objective function of a problem.

3.3.1 Thermal system encoding: If $N$ represents the number of thermal units, an $N \times 24$ matrix is needed to represent a complete operation schedule. Fig. 6 shows the 2D encoding scheme with raw binary representation. Each chromosome string contains $N \times$ 24 genes and each gene is assigned only one bit, where ' 0 ' indicates off-line and ' 1 ' indicates on-line.

\begin{tabular}{|c|c|c|c|c|c|c|c|c|}
\hline & 1 & 2 & 3 & . & - & . & . & 24 \\
\hline 1 & 1 & 0 & 0 & 1 & 1 & 0 & 0 & 0 \\
\hline 2 & 0 & 1 & 1 & 0 & 0 & 1 & 0 & 1 \\
\hline \multirow[t]{2}{*}{ 蒙： } & & & : & & & : & & \\
\hline & & & : & & & : & & \\
\hline $\mathrm{N}$ & 0 & 0 & 1 & 0 & 1 & 0 & 1 & 0 \\
\hline
\end{tabular}

Fig. 6 Encoding scheme for thermal system

3.3.2 Hydroelectric system encoding: Fig. 7 shows the encoding scheme that translates the encoded parameter, water discharges of each plant, into its binary representation. Using a plant's water discharge rather than the plant's generation output, the encoded parameter is more beneficial for dealing with difficult water balance constraints. For an HIP or a P/S plant, each chromosome string contains 24 genes to represent the solution for the hourly discharge schedule in a $24 \mathrm{~h}$ period, as shown in Figs. $7 a$ and $c$. For HCPs, each chromosome string contains $N \times 24$ genes to represent the solution for the hourly discharge schedule of the $N$ plants located on the same river system, as shown in Fig. $7 b$. Basically, each gene is assigned the same number of four bits to represent a normalised water discharge $q_{j}^{t}$. The resolution is equal to $1 / 2^{4}$ of the discharge difference from minimum to maximum. The additional one bit of $\mathrm{P} / \mathrm{S}$ plant encoding is used to identify whether the plant is in generating or in pumping mode.
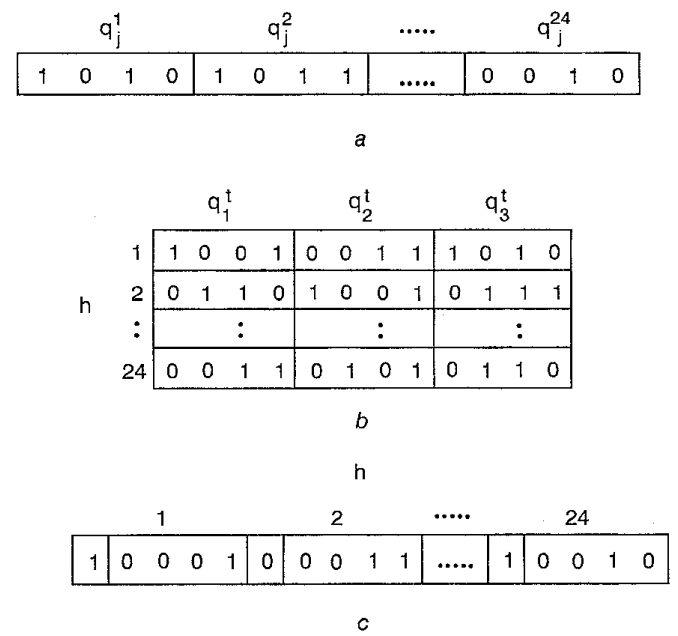

Fig.7 Encoding scheme for hydroelectric system a HIP $b$ River system with three HCPs $c$ P/S plant with four units

3.3.3 Thermal system decoding: Evaluation of a chromosome is accomplished by decoding the encoded chromosome string and computing the corresponding chromosome's fitness value. For ease of exposition, consider a $24 \mathrm{~h}$ case and assume that the $i$ th unit has the following operation data:

(i) minimal uptime $=6 \mathrm{~h}$

(ii) minimal downtime $=5 \mathrm{~h}$

(iii) initial status (IS) $=-2$ (i.e. the $i$ th unit has already been off line for $2 \mathrm{~h}$ )

IEE Proc-Gener. Transm. Distrib., Vol. 145, No. 4, July 1998 
The detailed decoding procedure that decodes the raw on/off status $u_{i}^{t}$ into the actual on/off schedule $U_{i}^{t}$ is illustrated in Fig. 8 and is summarised by the following rules:

Rule A: Check if the initial status satisfies minimal uptime/downtime constraints. If not, continue the initial operation status from hour 1 until satisfied

Rule B: Check if $u_{i}{ }^{t}=U_{i}^{t-1}$, then the $i$ th unit maintains the same operation status as the previous hour

Rule C: If the ith unit starts from hour $t$; it must remain on-line for at least $T_{i}^{u p}$ hours

Rule D: If the $i$ th unit shuts down from hour $t$, it must be kept off-line for at least $T_{i}^{\text {down }}$ hours

$\mathrm{h}$

IS $\begin{array}{llllllllll}1 & 2 & 3 & 4 & 5 & 6 & 7 & 8 & 9101112131415161718192021222324\end{array}$ \begin{tabular}{|l|l|l|l|l|l|l|l|l|l|l|l|l|l|l|l|l|l|l|l|l|l|l|}
\hline 1 & 0 & 1 & 0 & 0 & 0 & 0 & 1 & 0 & 1 & 0 & 0 & 1 & 1 & 1 & 1 & 0 & 0 & 1 & 0 & 1 & 1 & 0 \\
\hline
\end{tabular}

a

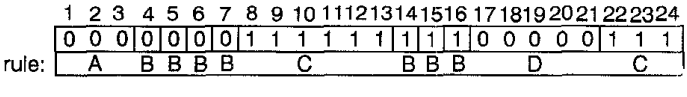

$b$

Fig.8 Example of proposed decoding algorithm for thermal system $a$ Raw on/off status $u_{i}$ $b$ On/off schedule $U_{i}^{t}$ after decoding

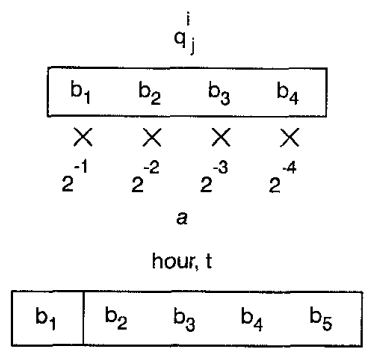

$b$

Fig.9 Decoding scheme for a hydroelectric system $a$ For HIP or HCP

$q_{j}^{t}=\Sigma_{i=1}^{4}\left(b_{i} \times 2^{-i}\right), b_{i} \in\{0,1\}$

$b$ For P/S plant with four unit

$b_{1}=0 \Rightarrow$ 'pumping mode'
$b_{1}=1 \Rightarrow$ 'generating mode'

3.3.4 Hydroelectric system decoding: Fig. 9 illustrates the decoding scheme for a hydroelectric system. For an HIP or an HCP, first decode each gene of the chromosome string to obtain the normalised discharge $q_{j}^{t}$ in decimal values as shown in Fig. $9 a$. Then, translate the normalised value $q_{j}^{t}$ to the actual value $Q_{j}{ }^{t}$ :

$$
Q_{j}^{t}=\underline{Q_{j}^{t}}+q_{j}^{t}\left(\overline{Q_{j}^{t}}-\underline{Q_{j}^{t}}\right)
$$

where and $\overline{Q_{j}^{t}}$ and $Q_{j}^{t}$ denote, respectively, the upper and lower bounds of $Q_{j}^{t}$. For an HCP, because of the hydraulic coupling, the discharge of an HCP is constrained by (i) the discharge limits of that plant (ii) the storage limits of the reservoir of that plant (iii) the storage limits of the reservoir of the downstream plant. Combining these constraints, the upper and lower bounds of the discharge of plant $j$ in hour $t$ can be derived as [8]:

$$
\begin{array}{r}
\overline{Q_{j}^{t}}=\min \left[\overline{Q_{j}},\left(V_{j}^{t-1}+Q_{j-1}^{t-\tau_{j-1}}+I_{j}^{t}-\underline{V_{j}}\right)\right. \\
\left.\left(-V_{j+1}^{t-1}-I_{j+1}^{t}+\overline{Q_{j+1}}+\overline{V_{j+1}}\right)\right]
\end{array}
$$

$$
\begin{array}{r}
\underline{Q_{j}^{t}}=\max \left[\frac{Q_{j}}{},\left(V_{j}^{t-1}+Q_{j-1}^{t-\tau_{j-1}}+I_{j}^{t}-\overline{V_{j}}\right),\right. \\
\left.\left(-V_{j+1}^{t-1}-I_{j+1}^{t}+\underline{Q_{j+1}}+\underline{V_{j+1}}\right)\right]
\end{array}
$$

For a $\mathrm{P} / \mathrm{S}$ plant, the first bit of a gene is used to identify whether the plant is in generating or in pumping mode. If it is in generating mode, the decoding algorithm is similar to an HIP. If it is in pumping mode, each bit of ' 1 ' indicates one pumping unit as shown in Fig. $9 b$.

\subsection{Fitness function}

In order to emphasise the 'best' chromosomes and speed up the convergence of the evolutionary process, fitness is normalised into the range between 0 and 1 . The fitness function of the $i$ th chromosome in the population is defined as:

$$
\operatorname{FIT}(i)=\frac{1}{1+k\left(\frac{\operatorname{cost}(i)}{\operatorname{cost}(\min )}-1\right)}
$$

where $\operatorname{cost}(i)$ is the corresponding solution cost of the $i$ th chromosome, and cost(min) is the solution cost of the highest ranking chromosome, i.e. the presently best chromosome, and $k$ is a scaling constant ( $k=50$ in this study).

\section{Numerical example}

The proposed GA approach was implemented in a sofiware package and tested on the Taipower generation system. This software package was written in Salford Fortran language and executed on a 486-66 personal computer. In addition to the common constraints listed in Section 2, the Taipower system has two additional characteristics that increase the difficulty of the problem [11]:

(i) The Taipower system is an isolated system, thus it must remain self-sufficient at all times. The $300 \mathrm{MW}$ system spinning reserve requirement must be satisfied each hour.

(ii) The large load fluctuations, especially at the noon lunch-break hours, are difficult to handle by thermal units due to their ramp rate limits.

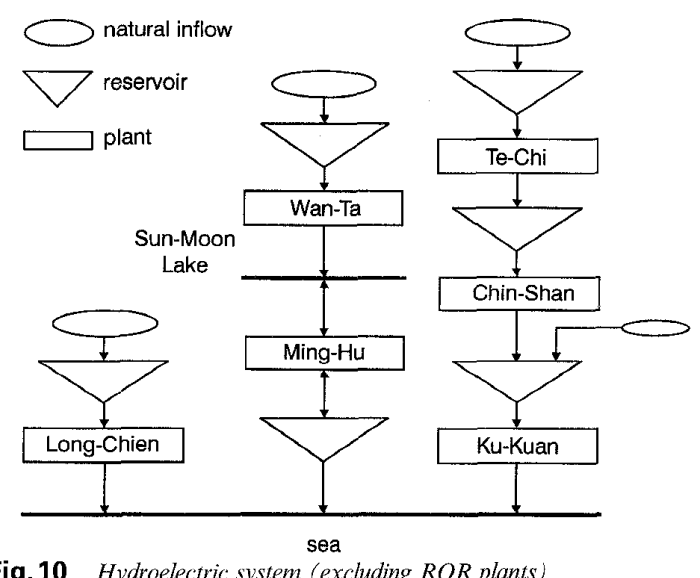

Fig. 10 Hydroelectric system (excluding ROR plants)

Fig. 10 is a schematic diagram of the hydroelectric system. The hydroelectric system consists of two HIPs, three HCPs located on the Ta-Chia river, one P/S plant with four units, and five ROR plants (not shown). 
Table 1: Characteristics of the hydroelectric system

\begin{tabular}{lcllccl}
\hline Plant & $\begin{array}{l}\text { Maximal } \\
\text { output, } \\
\text { MW }\end{array}$ & $\begin{array}{l}\text { Minimal } \\
\text { output, } \\
\mathrm{MW}\end{array}$ & $\begin{array}{l}\text { Maximal } \\
\text { discharge, } \\
\mathrm{m}^{3} / \mathrm{s}\end{array}$ & $\begin{array}{l}\text { Maximal } \\
\text { storage, } \\
\mathrm{k} \times \mathrm{m}^{3}\end{array}$ & $\begin{array}{l}\text { Natural } \\
\text { inflow, } \\
\mathrm{m}^{3} / \mathrm{s}\end{array}$ & Plant type \\
\hline Wan-Ta & 15 & 10 & 7.2 & 126930 & 7 & HIP \\
Long-Chien & 98 & 20 & 12.9 & 250 & 6 & HIP \\
Te-Chi & 234 & 60 & 177 & 254420 & 58 & HCP \\
Chin-Shan & 360 & 40 & 150 & 427 & - & HCP \\
Ku-Kuan & 180 & 30 & 73 & 7960 & 6 & HCP \\
Total & $887 \mathrm{MW}$ & & & & & \\
\hline
\end{tabular}

Table 2: Characteristics of the Ming-Hu P/S plant

\begin{tabular}{|c|c|c|c|c|c|}
\hline \multirow[b]{2}{*}{$\begin{array}{l}\text { Installed } \\
\text { capacity }\end{array}$} & \multirow{2}{*}{$\begin{array}{l}\text { Maximal } \\
\text { discharge, } \\
\mathrm{m}^{3} / \mathrm{s}\end{array}$} & \multirow{2}{*}{$\begin{array}{l}\text { Maximal } \\
\text { pumping, } \\
\mathrm{m}^{3} / \mathrm{s}\end{array}$} & \multicolumn{2}{|c|}{ Lower reservoir } & \multirow[b]{2}{*}{ Efficiency } \\
\hline & & & $\begin{array}{l}\text { Maximal } \\
\text { storage, } \\
\mathrm{k} \times \mathrm{m}^{3}\end{array}$ & $\begin{array}{l}\text { Minimal } \\
\text { storage, } \\
\mathrm{k} \times \mathrm{m}^{3}\end{array}$ & \\
\hline $250 \mathrm{MW} \times 4$ & 380 & 249 & 9756 & 1478 & 0.74 \\
\hline
\end{tabular}

Detailed characteristic data of the hydroelectric system are given in Tables 1 and 2. Some characteristics are described as follows $[11,12]$ :

(i) The generation output of ROR plants is prescheduled. The five ROR plants contribute a total of $91 \mathrm{MW}$ each hour.

(ii) The storage capacity of Sun-Moon Lake is large enough to be able to ignore its storage limitations.

(iii) Chin-Shan is a must-run unit because it is connected to Taipower's Automatic Generation Control (AGC) system. However, it has only a small reservoir.

(iv) There is a one hour travel time delay for water between the Chin-Shan and $\mathrm{Ku}-\mathrm{Kuan}$ plants.

The thermal system consists of 34 thermal units involving six large coal-fired units, eight small coalfired units, seven oil-fired units, ten gas turbine units, and three combined cycle units. For data on the characteristics of the 34-unit thermal system, please refer to [9]. The generation output of the six nuclear units are prescheduled as read-in data.

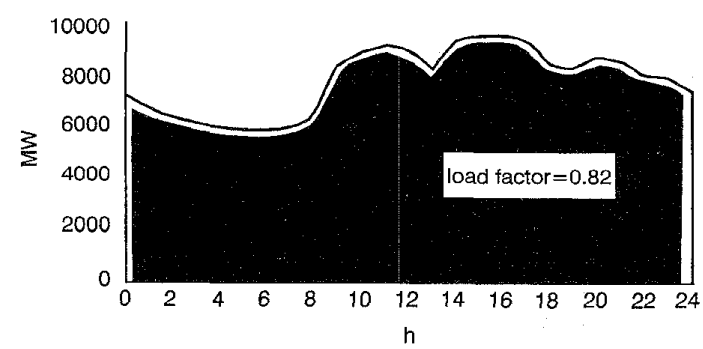

Fig.11 Summer weekday load profile

The software is tested on a weekday load profile as shown in Fig. 11. The optimal schedules for both hydro and thermal units are shown schematically in $[12,13]$ which show the total generation profile of the hydroelectric system and the complete hourly MW schedules for the individual thermal plants, respectively. From the above study, several interesting and important observations can be summarised as follows:

(i) The generation profile of both the hydroelectric system and the thermal system basically follow the load fluctuation that is consistent with our economic expectation.

(ii) Water is a very valuable natural resource. The hydroelectric system, excluding the $\mathrm{P} / \mathrm{S}$ plant, contributes $12,488 \mathrm{MWh}$ in one day. The hydroelectric plants are also the major source of system spinning reserve due to their fast response characteristics.

(iii) The Ming-Hu $\mathrm{P} / \mathrm{S}$ plant pumps up during off-peak hours and generates during peak load hours, resulting in a cost saving of 5.73 million NT dollars in one day.

(iv) The dispatching results of the coupled HCPs created by the proposed GA approach do not spill any valuable water resource.

(v) The reason the hydro plants do not generate to their maximum during peak hours is because of the system spinning reserve requirement.

(iv) The difficult minimal uptime/downtime contraints and ramp rate limits of each thermal unit are all satisfied.

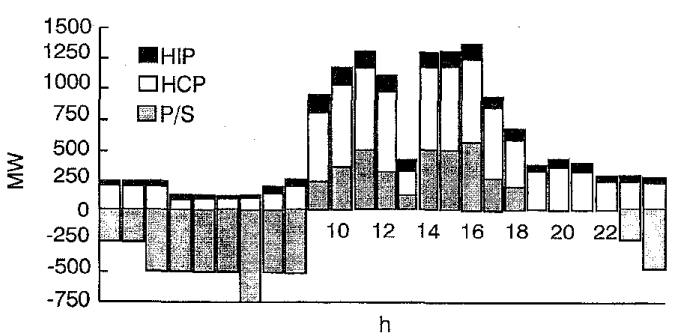

Fig. 12 Generation profiles of the hydroelectric system HCP: $1444 \mathrm{MWh}$

P/S: $3525.5 \mathrm{MWh}$ (generating) $4750 \mathrm{MWh}$ (pumping)

\section{Conclusions}

This paper presents a new methodology based on a GA for solving the daily HTGS problem of the Taipower system. For software subprograms for dispatching thermal units, HIPs, HCPs, and P/S plants have been developed and have been integrated as a complete, efficient software package. One of the advantages of the proposed approach is the flexibility of GA for modelling the difficult water balance constraints due to hydraulic coupling and the minimal uptime/downtime 


\begin{tabular}{|c|c|c|c|c|c|c|c|c|c|c|c|c|c|c|c|c|c|c|c|c|c|c|c|c|c|}
\hline \multirow[b]{2}{*}{ Unit } & \multirow[b]{2}{*}{ Type } & \multicolumn{24}{|c|}{ Hour } \\
\hline & & 01 & 02 & 03 & 04 & 05 & 06 & 07 & 08 & 09 & 10 & 11 & 12 & 13 & 14 & 15 & 16 & 17 & 18 & 19 & 20 & 21 & 22 & 23 & 24 \\
\hline 01 & $\mathrm{SC}$ & 72 & 80 & 68 & 64 & 48 & 64 & 40 & 74 & 80 & 80 & 80 & 80 & 72 & 74 & 80 & 80 & 80 & 72 & 74 & 80 & 74 & 72 & 74 & 68 \\
\hline 02 & SC & 120 & 120 & 120 & 120 & 102 & 107 & 73 & 109 & 120 & 120 & 120 & 120 & 98 & 102 & 120 & 120 & 120 & 104 & 110 & 120 & 114 & 102 & 110 & 98 \\
\hline 03 & $\mathrm{SC}$ & 190 & 190 & 190 & 190 & 190 & 190 & 162 & 190 & 190 & 190 & 190 & 190 & 190 & 190 & 190 & 190 & 190 & 190 & 190 & 190 & 190 & 190 & 190 & 190 \\
\hline 04 & $\mathrm{SC}$ & $\mathrm{U}$ & $\mathrm{U}$ & $\mathrm{U}$ & $\mathrm{U}$ & $\mathrm{U}$ & $\mathrm{U}$ & $\mathrm{U}$ & $\mathrm{U}$ & $\mathrm{U}$ & $\mathrm{U}$ & $\mathrm{U}$ & $\mathrm{U}$ & $\mathrm{U}$ & U & $\mathrm{U}$ & $\mathrm{U}$ & $\mathrm{U}$ & $\mathrm{U}$ & $\mathrm{U}$ & $\mathrm{U}$ & $\mathrm{U}$ & $\mathrm{U}$ & $\mathrm{U}$ & $\mathrm{U}$ \\
\hline 05 & SC & $\mathbf{U}$ & $\mathbf{U}$ & $\mathrm{U}$ & $\mathrm{U}$ & $\mathrm{U}$ & $\mathrm{U}$ & $\mathrm{U}$ & $\mathrm{U}$ & $\mathrm{U}$ & $\mathrm{U}$ & $\mathrm{U}$ & $\mathrm{U}$ & $\mathrm{U}$ & $\mathrm{U}$ & $\mathrm{U}$ & $\mathrm{U}$ & $\mathrm{U}$ & $\mathrm{U}$ & $\mathrm{U}$ & $\mathrm{U}$ & $\mathrm{U}$ & $\mathrm{U}$ & $\mathrm{U}$ & $\mathrm{U}$ \\
\hline 06 & $\mathrm{SC}$ & 129 & 140 & 122 & 116 & 94 & 118 & 78 & 114 & 140 & 140 & 140 & 140 & 112 & 127 & 140 & 140 & 140 & 118 & 120 & 140 & 132 & 108 & 116 & 104 \\
\hline 07 & $\mathrm{SC}$ & 292 & 300 & 300 & 263 & 228 & 274 & 211 & 300 & 300 & 300 & 300 & 300 & 289 & 300 & 300 & 300 & 300 & 300 & 300 & 300 & 300 & 300 & 300 & 300 \\
\hline 08 & $\mathrm{LC}$ & 300 & 300 & 300 & 300 & 300 & 300 & 300 & 300 & 300 & 300 & 300 & 300 & 300 & 300 & 300 & 300 & 300 & 300 & 300 & 300 & 300 & 300 & 300 & 300 \\
\hline 09 & $\mathrm{LC}$ & 300 & 300 & 300 & 300 & 300 & 300 & 300 & 300 & 300 & 300 & 300 & 300 & 300 & 300 & 300 & 300 & 300 & 300 & 300 & 300 & 300 & 300 & 300 & 300 \\
\hline 10 & $\mathrm{SC}$ & 300 & 300 & 300 & 300 & 300 & 300 & 256 & 300 & 300 & 300 & 300 & 300 & 300 & 300 & 300 & 300 & 300 & 300 & 300 & 300 & 300 & 300 & 300 & 300 \\
\hline 11 & Oil & U & $\mathrm{U}$ & $\mathrm{U}$ & U & U & $\mathrm{U}$ & U & $\mathrm{U}$ & $\mathrm{U}$ & $\mathrm{U}$ & $\mathrm{U}$ & $\mathrm{U}$ & $\mathrm{U}$ & $\mathrm{U}$ & $\mathrm{U}$ & $\mathrm{U}$ & $\mathrm{U}$ & U & $\mathrm{U}$ & $U$ & $\mathrm{U}$ & U & U & $\mathrm{U}$ \\
\hline 12 & Oil & $\mathrm{U}$ & $\mathrm{U}$ & $\mathrm{U}$ & $\mathrm{U}$ & U & $\mathrm{U}$ & $\mathrm{U}$ & $\mathrm{U}$ & $\mathrm{U}$ & $\mathrm{U}$ & $\mathrm{U}$ & $\mathrm{U}$ & $\mathrm{U}$ & $\mathrm{U}$ & $U$ & $\mathrm{U}$ & $\mathrm{U}$ & U & $U$ & $\mathrm{U}$ & $\mathrm{U}$ & $\mathrm{U}$ & U & $\mathrm{U}$ \\
\hline 13 & Oil & U & $\mathrm{U}$ & $\mathrm{U}$ & U & $\mathrm{U}$ & $\mathrm{U}$ & $\mathrm{U}$ & $\mathrm{U}$ & $\mathrm{U}$ & $\mathrm{U}$ & $\mathrm{U}$ & $\mathrm{U}$ & $\mathrm{U}$ & $\mathrm{U}$ & $\mathrm{U}$ & $\mathrm{U}$ & $\mathrm{U}$ & U & $\mathrm{U}$ & $\mathrm{U}$ & $\mathrm{U}$ & $\mathrm{U}$ & U & $\mathrm{U}$ \\
\hline 14 & Oil & 125 & 0 & 0 & 0 & 0 & 0 & 0 & 0 & 240 & 480 & 500 & 500 & 500 & 500 & 500 & 500 & 500 & 500 & 500 & 500 & 500 & 500 & 500 & 500 \\
\hline 15 & Oil & $\mathrm{U}$ & $\mathrm{U}$ & $\mathrm{U}$ & $\mathrm{U}$ & $\mathrm{U}$ & $\mathrm{U}$ & $\mathrm{U}$ & $\mathrm{U}$ & $\mathrm{U}$ & U & $\mathrm{U}$ & $\mathrm{U}$ & $\mathrm{U}$ & $\mathrm{U}$ & U & $\mathrm{U}$ & $\mathrm{U}$ & $\mathrm{U}$ & $\mathrm{U}$ & $\mathrm{U}$ & $\mathrm{U}$ & $\mathrm{U}$ & $\mathrm{U}$ & $\mathrm{U}$ \\
\hline 16 & Oil & 0 & 0 & 0 & 0 & 0 & 0 & 0 & 0 & 240 & 456 & 500 & 500 & 500 & 500 & 500 & 500 & 500 & 500 & 500 & 500 & 500 & 500 & 500 & 500 \\
\hline 17 & Oil & 157 & 173 & 125 & 0 & 0 & 0 & 0 & 0 & 0 & 0 & 0 & 0 & 240 & 348 & 412 & 386 & 500 & 285 & 363 & 500 & 500 & 274 & 348 & 267 \\
\hline 18 & $\mathrm{LC}$ & 500 & 500 & 500 & 500 & 500 & 500 & 500 & 500 & 500 & 500 & 500 & 500 & 500 & 500 & 500 & 500 & 500 & 500 & 500 & 500 & 500 & 500 & 500 & 500 \\
\hline 19 & LC & 500 & 500 & 500 & 500 & 500 & 500 & 500 & 500 & 500 & 500 & 500 & 500 & 500 & 500 & 500 & 500 & 500 & 500 & 500 & 500 & 500 & 500 & 500 & 500 \\
\hline 20 & LC & 550 & 550 & 550 & 550 & 550 & 550 & 550 & 550 & 550 & 550 & 550 & 550 & 550 & 550 & 550 & 550 & 550 & 550 & 550 & 550 & 550 & 550 & 550 & 550 \\
\hline 21 & LC & 550 & 550 & 550 & 550 & 550 & 550 & 550 & 550 & 550 & 550 & 550 & 550 & 550 & 550 & 550 & 550 & 550 & 550 & 550 & 550 & 550 & 550 & 550 & 550 \\
\hline 22 & Gas & 0 & 0 & 0 & 0 & 0 & 0 & 0 & 0 & 0 & 0 & 0 & 0 & 0 & 0 & 0 & 0 & 0 & 0 & 0 & 0 & 0 & 0 & 0 & 0 \\
\hline 23 & Gas & 0 & 0 & 0 & 0 & 0 & 0 & 0 & 0 & 0 & 0 & 0 & 0 & 0 & 0 & 0 & () & () & 0 & 0 & 0 & 0 & 0 & 0 & 0 \\
\hline 24 & Gas & 0 & 0 & 0 & 0 & 0 & 0 & 0 & 0 & 0 & 0 & 0 & 0 & 0 & 0 & 0 & 0) & () & 0 & () & 0 & 0 & 0 & 0 & 0 \\
\hline 25 & Gas & 0 & 0 & 0 & 0 & 0 & 0 & 0 & 0 & 0 & 0 & 0 & 0 & 0 & 0 & 0 & 0 & 0 & 0 & 0 & 0 & 0 & 0 & 0 & 0 \\
\hline 26 & Gas & 0 & 0 & 0 & 0 & 0 & 0 & 0 & 0 & 0 & 0 & 0 & 0 & 0 & 0 & 0 & 0 & () & 0 & () & 0 & 0 & 0 & 0 & 0 \\
\hline 27 & Gas & 0 & 0 & 0 & 0 & 0 & 0 & 0 & 0 & 0 & 0 & 0 & 0 & 0 & 0 & 0 & 0 & 0 & 0 & 0 & 0 & 0 & 0 & 0 & 0 \\
\hline 28 & Gas & 0 & 0 & 0 & 0 & 0 & 0 & 0 & 0 & 0 & 0 & 0 & 0 & 0 & 0 & 0 & 0 & 0 & 0 & 0 & 0 & 0 & 0 & 0 & 0 \\
\hline 29 & Gas & 0 & 0 & 0 & 0 & 0 & 0 & 0 & 0 & 0 & 0 & 0 & 0 & 0 & 0 & 0 & 0 & 0 & 0 & 0 & 0 & 0 & 0 & 0 & 0 \\
\hline 30 & Gas & 0 & 0 & 0 & 0 & 0 & 0 & 0 & 0 & 0 & 0 & 0 & 0 & 0 & 0 & 0 & 0 & 0 & ) & 0 & 0 & 0 & 0 & 0 & 0 \\
\hline 31 & Gas & 0 & 0 & 0 & 0 & 0 & 0 & 0 & 0 & 0 & 0 & 0 & 0 & 0 & 0 & 0 & 0 & () & 0) & 0 & 0 & 0 & 0 & 0 & 0 \\
\hline 32 & Com & 0 & 0 & 0 & 0 & 0 & 114 & 65 & 167 & 315 & 273 & 309 & 304 & 227 & 235 & 301 & 265 & 247 & 117 & 130 & 294 & 156 & 0 & 0 & 0 \\
\hline 33 & Com & 0 & 0 & 0 & 0 & 0 & 0 & 0 & 0 & 135 & 102 & 217 & 198 & 188 & 204 & 221 & 208 & 195 & 0 & 0 & 0 & () & 0 & 0 & 0 \\
\hline 34 & Com & U & $\mathrm{U}$ & $\mathrm{U}$ & U & $\mathrm{U}$ & $\mathrm{U}$ & $\mathrm{U}$ & $\mathrm{U}$ & $\mathrm{U}$ & $\mathrm{U}$ & $\mathrm{U}$ & $\mathrm{U}$ & $\mathrm{U}$ & $\mathrm{U}$ & U & U & U & U & U & U & U & U & U & $U$ \\
\hline
\end{tabular}

Fig. 13 Complete $M W$ schedules of the thermal units

$\mathrm{SC}=$ small coal-fired unit, $\mathrm{LC}=$ large coal-fired unit, Oil = oil-fired unit, Gas $=$ gas turbine unit, Com $=$ combined cycle unit, $\mathrm{U}=$ unavailable unit

constraints of thermal units. The effects of net head and water travel time of hydro plants are also considered. Numerical results from an actual utility system indicate the attractive properties of the GA approach in practical application, which are a highly optimal solution and more robust convergence behaviour.

\section{Acknowledgments}

Financial support for this research by the National Science Council of the Republic of China under Grant No. NSC84 2213-E-011-035 is greatly appreciated.

\section{References}

1 WOOD, A.J., and WOLLENBERG, B.F.: 'Power generation, operation and control' (Wiley, New York, 1984)

2 EL-HAWARY, M.E.: 'An overview of scheduling functions in hydrothermal electric power systems', Proceedings of 1991 IASTED international conference, March 1991, pp. 1-37

3 RUZIC, S., VUCKOVIC, A., and RAJAKOVIC, N.: 'A flexible approach to short-term hydrothermal coordination, Part I \& II', IEEE Trans. Power Syst., 1996, 11, pp. 1564-1578
4 GUAN, X., and LUH, P.B.: 'Nonlinear approximation method in Lagrangian relaxation-based algorithm for hydrothermal scheduling', IEEE Trans. Power Syst., 1995, 10, pp. 772-778

5 GOLDBERG, D.E.: 'Genetic algorithm in search, optimization, and machine learning' (Addison-Wesley, 1989)

6 DAVIS, L.: 'Handbook of genetic algorithms' (Van Nostrand Reinhold, 1991)

7 NARA, K., SHIOSE, A., KITAGAWA, M., and SHIHARA, T.: 'Implementation of genetic algorithm for distribution systems loss minimum reconfiguration', IEEE Trans. Power Syst., 1992, 7, (3), pp. $1044-1050$

8 CHEN, P.H., and CHANG, H.C.: 'Genetic aided scheduling of hydraulically coupled plants in hydrothermal coordination', IEEE Trans. Power Syst., 1996, 11, (2), pp. 975-981

9 CHEN, P.H., and CHANG, H.C.: 'Large-scale economic dispatch by genetic algorithm', IEEE Trans. Power Syst., 1995, 10, (4), pp. 1919-1926

10 WU, R.N., LEE, T.H., and HILL, E.F.: 'An investigation of the accuracy and the characteristics of the peak-shaving method applied to production cost calculations', IEEE Trans. Power applied to production cost calcu
Syst., 1989, 4, (3), pp. 1043-1049

11 SUN, D.I.: "Generating units (hydro, thermal and pumped-storage) optimal dispatch'. Annual Research and Development Report, Taipower, pp. 1-81, 1988

12 CHEN, P.H.: 'Generation scheduling of hydraulically coupled plants'. Masters Thesis, Department of Electrical Engineering, National Tsing-Hua University, 1989 